\title{
Faktor Pemilihan E Marketplace di Indonesia dari Perspektif Penjual (Studi Kasus: Tokopedia dan Shopee) \\ Hafni Ramadhani ${ }^{1}$, Teduh Dirgahayu ${ }^{2}$ \\ Universitas Islam Indonesia ${ }^{1,2}$ \\ hafniramadhani94@gmail.com, teduh.dirgahayu@uii.ac.id
}

\begin{abstract}
Abstrak - Pertumbuhan pelaku e-commerce di Indonesia mengalami peningkatan tujuh belas persen, dengan jumlah seluruh usaha e-commerce sebanyak 26,2 juta unit dalam sepuluh tahun. Banyaknya pelaku e-commerce ini didominasi oleh e-marketplace. E-marketplace sendiri mengalami persaingan yang cukup ketat. Hasil studi menunjukkan bahwa Tokopedia dan Shopee merupakan emarketplace yang memiliki rata-rata menit per akses dan jumlah pengunjung yang tinggi diantara emarketplace lain. E-marketplace sebagai wadah yang mempertemukan antara penjual dan pembeli, semestinya mempertimbangkan faktor yang membuat penjual dan pembeli bertahan, namun penelitian dari perspektif penjual belum banyak dilakukan. Untuk itu, penelitian berbasis studi literatur ini dilakukan guna mendapatkan faktor dan indikator yang dapat menarik penjual untuk memasarkan produknya ke situs e-marketplace Tokopedia dan Shopee. Pengumpulan data menggunakan kuisioner dengan skala likert 1-4 kepada 300 responden. Hasil penelitian menemukan 5 faktor dengan 50 indikator yang dapat menarik penjual untuk memasarkan produknya ke situs emarketplace Tokopedia dan Shopee. Yakni faktor kepercayaan penjual dengan 15 indikator, pembayaran dan pengiriman dengan 14 indikator, kualitas situs e-marketplace dengan 10 indikator, biaya dengan 7 indikator, dan nama baik produk dengan 4 indikator.
\end{abstract}

Kata kunci: faktor; indikator; e-marketplace; tokopedia; shopee;

\begin{abstract}
The Indonesia e-commerce growth rate has incresead by seventeen percent, with the total number of e-commerce businesses totaling 26.2 million units in ten years. This number is dominated by e-marketplaces. e-marketplace itself is experiencing fierce competition. The study results show that Tokopedia and Shopee are e-marketplaces that have an average of minutes per access and a high number of visitors among other e-marketplaces. E-marketplaces as a forum that brings together sellers and buyers should consider the factors that make sellers and buyers survive, but research from the seller's perspective has not been done much. For this reason, this literature-based study is conducted to obtain factors and indicators that can attract sellers to sell their products on the Tokopedia and Shopee e-marketplace sites. Data collection using a questionnaire with a Likert scale 1-4 to 300 respondents. The results found 5 factors and 50 indicators that could attract sellers to sell their products to the Tokopedia and Shopee e-marketplaces sites. That is seller trust with 15 indicators, payment and delivery with 14 indicators, e-marketplaces site quality with 10 indicators, cost with 7 indicators, product reputation with 4 indicators.
\end{abstract}

Keyword : factor; indicator; e-marketplace; tokopedia; shopee;

\section{Latar Belakang}

Menurut data Badan Pusat Statistik (BPS), pertumbuhan pelaku e-commerce di Indonesia mengalami peningkatan $17 \%$, dengan jumlah seluruh usaha e-commerce sebanyak 26,2 juta unit dalam sepuluh tahun [1]. E-commerce ialah transaksi antara penjual dan pembeli untuk bertukar barang, jasa, ataupun informasi menggunakan situs internet [19]. Peningkatan ini terjadi karena adanya dukungan dari Kementrian Komunikasi dan Informatika (KOMINFO) melalui program gerakan 1000 startup [4]. Sesuai dengan visi pemerintah untuk menjadikan Indonesia sebagai pemimpin ekonomi digital Asia Tenggara pada 2020 [34].

Banyaknya pertumbuhan situs e-commerce di Indonesia menyebabkan persaingan. Tahun 2017 terdapat hasil studi seperti pada tabel 1 dari IlmuOne Data mengenai 10 peringkat teratas situs e-commerce di Indonesia, dan 6 dari 10 peringkat teratas tersebut merupakan e-marketplace [12]. Data studi diperoleh dari comScore, penyedia data standar pengukuran pengguna online di Indonesia yang ditunjuk oleh Badan Ekonomi Kreatif (Bekraf) [6]. Kemudian Tahun 2018 terdapat hasil studi comScore mengenai 5 situs e-commerce di Indonesia yang memiliki pertumbuhan pengunjung tertinggi [14]. Hasil studi seperti pada tabel 2 menunjukkan bahwa 4 dari 5 situs e-commerce tersebut merupakan $e$ marketplace.

E-marketplace ialah wadah perdagangan via internet yang dikelola oleh satu pihak, namun barang yang diperjualbelikan disediakan oleh penjual pihak ketiga yang bergabung dalam wadah perdagangan

Faktor Pemilihan E Marketplace di Indonesia dari Perspektif Penjual (Studi Kasus: Tokopedia dan Shopee) 
tersebut [16]. Penjual pihak ketiga ini dapat membuat akun dan menawarkan barang yang akan dijual kepala pembeli menggunakan fasilitas yang telah disediakan pada e-marketplace tanpa perlu membuat situs jual beli pribadi. Tanpa adanya penjual, maka tidak akan ada pembeli, dan tidak akan ada transaksi jual beli dalam e-marketplace. Dalam transaksi jual beli di dalam $e-$ marketplace digunakan rekening bersama yang melibatkan pihak ke tiga. Sistem kerja rekening bersama dimulai ketika pembeli melakukan pemesanan barang pada $e-$ marketplace, kemudian pembeli melakukan pembayaran ke rekening bersama milik pihak ketiga. Setelah pembayaran dikonfirmasi oleh e-marketplace, e-marketplace memberitahukan kepada penjual untuk mengirimkan pesanan sesuai permintaan pembeli. Setelah pembeli mendapatkan barang sesuai dengan yang telah dipesan, pembeli melakukan konfirmasi penerimaan barang dan e-marketplace melepaskan dana ke penjual [24, 31].

Tabel 1. Lima Peringkat Teratas EMarketplace di Indonesia 2017

\begin{tabular}{|c|l|c|c|c|}
\hline & $\begin{array}{c}\text { E- } \\
\text { Marketplace }\end{array}$ & $\begin{array}{c}\text { Total } \\
\text { Populasi } \\
\text { unik }\end{array}$ & $\begin{array}{c}\text { Rata- } \\
\text { Rata } \\
\text { menit/ } \\
\text { akses }\end{array}$ & $\begin{array}{c}\text { Tahun } \\
\text { Berdiri }\end{array}$ \\
\hline 1 & Tokopedia & 14.401 .000 & 4.7 & 2009 \\
\hline 2 & Elevenia & 12.872 .000 & 1.5 & 2014 \\
\hline 3 & Shopee & 11.301 .000 & 16 & 2015 \\
\hline 4 & Bukalapak & 10.407 .000 & 2.4 & 2010 \\
\hline 5 & Qoo10 & 7.689 .000 & 0.8 & 2012 \\
\hline
\end{tabular}

Tabel 2. Empat E-Marketplace di Indonesia Dengan Pertumbuhan Pengunjung Tertinggi 2018

\begin{tabular}{|c|l|c|c|}
\hline & $\begin{array}{c}\text { E- } \\
\text { Marketplace }\end{array}$ & $\begin{array}{c}\text { Jumlah } \\
\text { Pengujung }\end{array}$ & $\begin{array}{c}\text { Pertumbuhan } \\
\text { Pengunjung }\end{array}$ \\
\hline 1 & Shopee & 28.000 .000 & $+130 \%$ \\
\hline 2 & Bukalapak & 26.000 .000 & $+89 \%$ \\
\hline 3 & Tokopedia & 32.000 .000 & $+70 \%$ \\
\hline 4 & Elevenia & 1.700 .000 & $+8 \%$ \\
\hline
\end{tabular}

E-marketplace di Indonesia bersaing dengan cukup ketat. Meskipun sudah mencapai peringkat teratas, e-marketplace masih perlu bersaing untuk membuat pengunjungnya bertahan dan semakin bertambah. Bila dilihat secara keseluruhan data pada tabel 1 dan tabel 2, Tokopedia dan Shopee adalah kedua e-marketplace memiliki data paling menarik. Menarik karena Tokopedia dan Shopee memiliki rata-rata pengguna yang ingin menghabiskan waktu berlama-lama untuk mengaksesnya, yang tercermin dari data menit setiap kali akses. Tokopedia dan Shopee juga memiliki data jumlah pengunjung yang lebih tinggi dibandingkan dengan e-marketplace yang lain.

Penelitian tentang e-marketplace sudah cukup banyak dilakukan, baik e-marketplace secara umum, maupun khusus terhadap suatu e-marketplace tertentu. Namun banyak penelitian yang masih melihat dari perspektif pembeli. Penelitian dari perspektif penjual belum banyak dilakukan. Padahal pembeli dan penjual memiliki pandangan yang berbeda ketika menggunakan e-marketplace [18, 34] . Pembeli cenderung mempertimbangkan lebih banyak faktor ketika memilih untuk melakukan transaksi di e-marketplace. Berdasarkan perbedaan padangan bagi pembeli dan penjual ini, maka perlu dilakukan penelitian dari perspektif penjual. Jika merubah sudut pandang penelitian mengenai penggunaan emarketplace, maka akan merubah faktor. Terlebih jika merubah subjek e-marketplace yang diteliti, tentu akan menghasilkan faktor yang berbeda pula [34].

Dari latar belakang diatas, maka disusun rumusan masalah: faktor-faktor apa saja yang dapat menarik penjual untuk memasarkan produknya ke situs e-marketplace Tokopedia dan Shopee?

Pada penelitian ini, pembahasan masalah dibatasi pada perspektif penjual Tokopedia dan Shopee di Indonesia. Pembentukan faktor didasarkan kepada scree plot dan nilai factor loading dengan nilai di atas 0,3 [9]. Tujuan yang ingin dicapai dari penelitian ini ialah untuk mengetahui faktor dan indikator yang dapat dipertimbangkan oleh e-marketplace untuk menarik penjual agar mau memasarkan produknya ke situs mereka.

\section{Kajian Pustaka}

a. Perspektif Pembeli terhadap E-Marketplace

- Tujuh faktor keberhasilan dari proses virtualisasi dalam perspektif e-commerce di Indonesia, yakni kualitas situs, kualitas citra produk, nama baik merek, pelayanan pelanggan, pembayaran, waktu pengiriman, dan harga produk [22].

- Ulasan produk menjadi salah satu fitur penting terhadap minat pembelian. Namun bukan faktor yang menyebabkan meningkatnya kepercayaan pelanggan. [8].

- Kualitas informasi, kualitas sistem, kualitas layanan secara positif berpengaruh signifikan terhadap kepuasan pengguna. Kepuasan pengguna secara positif berpengaruh signifikan terhadap minat pembelian [33].

- Kepercayaan pembeli kepada penjual dipengaruhi oleh ulasan positif penjual. Kepercayaan pada sistem pembayaran elektronik dipengaruhi oleh kualitas 
pembayaran elektronik, rekomendasi dari orang lain, dan manfaat yang diperoleh dengan menggunakan sistem pembayaran elektronik tersebut [32].

- Kulitas layanan, reputasi e-marketplace, dan kepercayaan merupakan indikator yang paling mempengaruhi konsumen dalam minat pembelian [17].

- Pengaruh kualitas situs dan kepercayaan berpengaruh terhadap loyalitas pelanggan e-marketplace [3].

- Keamanan, kemudahan, kepercayaan dan risiko kinerja secara parsial berpengaruh positif signifikan terhadap minat pembelian secara online. Sedangkan yang paling dominan dalam mempengaruhi minat pembelian secara online ialah keamanan [28].

- Fitur pemilihan harga dan ulasan produk berpengaruh secara positif dan tidak signifikan. Kemudahan penggunaan dan keamanan berpengaruh secara positif dan signifikan. Kemudahan penggunaan sangat berpengaruh terhadap keputusan pembelian [29].

b. Perspektif Penjual terhadap E-Marketplace

- Pembeli dan penjual sebagai komponen penting dalam e-marketplace memiliki pandangan yang berbeda untuk menggunakan e-marketplace [18].

- Hal yang mendukung penjual menggunakan e-commerce ialah kemudahan penggunaan, tersedianya teknologi infrastruktur, peningkatan komunikasi pelanggan, dan dorongan dari jumlah penguna yang banyak [11].

- Kepuasan, citra e-marketplace, biaya, promosi dan layanan yang memiliki nilai tambah memiliki dampak positif pada loyalitas penjual. Kepuasan adalah faktor yang memiliki pengaruh terbesar terhadap loyalitas penjual. [22].

- Fitur ulasan penjual pada e-marketplace merupakan penentu utama variasi harga. Di mana variasi harga merupakan seleksi nyata antar penjual untuk dapat menarik pembeli [20].

Berdasarkan 12 penelitian terdahulu tersebut, penulis menemukan 50 indikator yang kemudian akan dijabarkan dalam pernyataan kuisioner pada penelitian ini.

\section{Metode Penelitian}

\section{a. Jenis Penelitian}

Penelitian ini merupakan penelitian kuantitatif, untuk meneliti suatu populasi atau sampel tertentu. Pengambilan sampel menggunakan teknik proportionate stratified random sampling, pengumpulan data menggunakan instrumen penelitian, analisis data bersifat kuantitatif atau statistik. Penelitian ini menggunakan pendekatan deskriptif untuk mendeskripsikan objek atau hasil penelitian, melalui data atau sampel yang telah terkumpul [30].

\section{b. Populasi dan Sampel}

Populasi penelitian ini adalah seluruh penjual yang memasarkan barang mereka di e-marketplace Tokopedia dan Shopee. Populasi penjual di Tokopedia pada April 2020 sejumlah 7,8 juta penjual [15]. Sedangkan penjual aktif di Shopee lebih dari 2,5 juta orang pada Oktober 2019 [7]. Penentuan sampel penelitian yang merepresentaiskan populasi ialah 5 hingga 10 kali jumlah indikator penelitian [37]. Pada penelitian ini terdapat 50 indikator, maka jumlah sampel minimal $50 \times 5$ $=250$ sampel dan maksimal $50 \times 10=500$ sampel. Sedangkan jumlah sampel yang baik untuk analisis faktor ialah 300 sampel [26]. Berdasarkan kedua hal tersebut, maka ditetapkan jumlah sampel yang diambil adalah 300 sampel, dengan komposisi 150 orang penjual di Tokopedia dan 150 orang penjual di Shopee.

\section{c. Kuisioner}

Pada penelitian ini dilakukan penyebaran kuesioner untuk mendapatkan data. Kuesioner menggunakan skala likert bernilai 1-4, dengan makna sebagai berikut:

$$
\begin{aligned}
& 1 \text { = sangat tidak setuju (STS) } \\
& 2=\text { tidak setuju (TS) } \\
& 3=\text { setuju (S) } \\
& 4 \text { = sangat setuju (SS) }
\end{aligned}
$$

Pilihan jawaban dengan skala likert 4 digunakan untuk mengurangi kecenderungan untuk memilih nilai tengah, yang disebabkan responden ragu dalam memilih pernyataan [2].

\section{d. Uji Validitas dan Reliabilitas}

Uji validitas digunakan untuk mengukur valid atau tidaknya suatu item dalam kuesioner, sehingga kuisioner yang digunakan dapat dipercaya [30]. Uji validitas dilakukan dengan menggunakan teknik corrected itemtotal correlation. Suatu item dikatakan valid, jika rhitung $\geq$ rtabel. Nilai rtabel ialah 0.113 dengan sampel 300 responden dan taraf signifikansi $5 \%$. Sedangkan uji reliabitilas digunakan untuk melihat konsistensi data, meski diukur dalam waktu yang berbeda-beda. Suatu instrumen dikatakan reliabel, jika cronbach's alpha > 0,6.

\section{e. Analisis Faktor}

Analisis faktor merupakan multivariate interdependence techniques, yakni tidak ada variabel dependen maupun independen dalam penelitian. Sejumlah variabel awalnya saling bebas satu sama lain. Analisis faktor

Faktor Pemilihan E Marketplace di Indonesia dari Perspektif Penjual (Studi Kasus: Tokopedia dan Shopee) 
digunakan untuk menemukan hubungan antar variabe, sehingga ditemukan kelompok baru dengan mempertahankan sebanyak mungkin informasi yang ada [25].

Pada penelitian ini dilakukan Confirmatory Factor Analysis (CFA) untuk mengkonfirmasi keakuratan konstruk yang terdiri atas sejumlah variabel. Konstruk dalam ilmu statistika dinamakan faktor atau variabel laten. Peneliti merujuk kepada variabel laten yang ada pada literatur terdahulu dari perspektif pembeli terhadap penggunaan e-commerce ataupun emarketplace. Langkah analisis faktor adalah sebagai berikut [9, 25]:

- Kaiser-Meyer-Olkin (KMO) Measure of Sampling Adequency dan Barlett Test of Spericity, untuk membandingkan koefisien korelasi yang diamati dengan koefisien korelasi parsial. Agar analisis faktor dapat dilanjutkan, maka nilai KMO harus $>0,5$. Sedangkan barlett test digunakan untuk mengetahui apakah ada korelasi yang signifikan antar indikator suatu faktor. Nilai siginifkansi ini harus $<0,005$ agar analisis faktor dapat dilanjutkan.

- Measure of Sampling Adequancy (MSA), untuk mengukur kecukupan sampling setiap indikator individual. Nilai MSA harus $>0,5$ agar analisis faktor dapat dilanjutkan.

- Scree Plot, menggambarkan seluruh item penelitian. Scree plot digunakan untuk menentukan jumlah faktor yang terbentuk dengan cara melihat siku yang terbentuk sebagai batas penentuan jumlah faktor.

- Factor matrix dan Rotated Factor Matrix, untuk menentukan distribusi indikator ke dalam faktor baru. Interpretasi ini didasarkan kepada nilai factor loading yang paling tinggi. Indikator yang memiliki factor loading $<0,3$ artinya memiliki kontribusi yang lemah terhadap faktor baru.

- Uji Kesesuaian Model, adalah sebagai berikut [27]:

- Chi-square, semakin kecil nilainya maka semakin sesuai antara model teori dengan data sampel.

- Significance Level, dengan nilai <0,05.

- Comparative Fit Index (CFI), jika nilai CFI $\geq 0,90$ berarti merupakan good fit, sedangkan $0,80 \leq \mathrm{CFI} \leq 0,90$ disebut marginal fit.

- Root Mean Square Error of Approximation (RMSEA), merupakan kriteria pemodelan struktur kovarian dengan mempertimbangkan kesalahan yang mendekati populasi. Model dinilai close fit jika RMSEA $\leq 0,05$, good fit jika
$0,05<$ RMSEA $\leq 0,08$, marginal fit jika $0,08 \leq$ RMSEA $\leq 0,10$, dan poor fit jika > 0,10 .

\section{Hasil}

a. Hasil Uji Validitas

Tabel 3. Hasil Uji Validitas

\begin{tabular}{|c|c|c|}
\hline Kode & rhitung & Keterangan \\
\hline KP1 & 0,471 & Valid \\
\hline KP2 & 0,459 & Valid \\
\hline KP3 & 0,495 & Valid \\
\hline KS1 & 0,542 & Valid \\
\hline KS2 & 0,535 & Valid \\
\hline KS3 & 0,445 & Valid \\
\hline PP1 & 0,464 & Valid \\
\hline PP2 & 0,302 & Valid \\
\hline PB1 & 0,331 & Valid \\
\hline PB2 & 0,486 & Valid \\
\hline PB3 & 0,518 & Valid \\
\hline PB4 & 0,577 & Valid \\
\hline PK1 & 0,530 & Valid \\
\hline PK2 & 0,119 & Valid \\
\hline PK3 & 0,469 & Valid \\
\hline PK4 & 0,408 & Valid \\
\hline PK5 & 0,361 & Valid \\
\hline KI1 & 0,418 & Valid \\
\hline $\mathrm{KI} 2$ & 0,513 & Valid \\
\hline FU1 & 0,563 & Valid \\
\hline FU2 & 0,490 & Valid \\
\hline FU3 & 0,449 & Valid \\
\hline Bl1 & 0,395 & Valid \\
\hline $\mathrm{BI} 2$ & 0,423 & Valid \\
\hline $\mathrm{BI} 3$ & 0,365 & Valid \\
\hline $\mathrm{PH} 1$ & 0,522 & Valid \\
\hline UPR1 & 0,485 & Valid \\
\hline RK1 & 0,501 & Valid \\
\hline UPJ1 & 0,573 & Valid \\
\hline JP1 & 0,463 & Valid \\
\hline JP2 & 0,567 & Valid \\
\hline KM1 & 0,566 & Valid \\
\hline LY1 & 0,483 & Valid \\
\hline PR1 & 0,551 & Valid \\
\hline PR2 & 0,424 & Valid \\
\hline KA1 & 0,441 & Valid \\
\hline KA2 & 0,599 & Valid \\
\hline ES1 & 0,563 & Valid \\
\hline NB1 & 0,587 & Valid \\
\hline HP1 & 0,557 & Valid \\
\hline $\mathrm{KC} 1$ & 0,541 & Valid \\
\hline JPG1 & 0,472 & Valid \\
\hline MP1 & 0,546 & Valid \\
\hline RPG1 & 0,352 & Valid \\
\hline RMP1 & 0,593 & Valid \\
\hline KPG1 & 0,630 & Valid \\
\hline KPG2 & 0,665 & Valid \\
\hline KPU1 & 0,550 & Valid \\
\hline LO1 & 0,591 & Valid \\
\hline LO2 & 0,642 & Valid \\
\hline
\end{tabular}

Faktor Pemilihan E Marketplace di Indonesia dari Perspektif Penjual (Studi Kasus: Tokopedia dan Shopee) 
Berdasarkan data pada tabel 3 , semua nilai

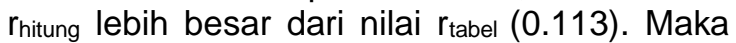
50 item pernyataan yang ada dalam kuesioner dapat dikatakan valid.

b. Hasil Uji Reliabilitas

Tabel 4. Hasil Uji Reliabilitas

\begin{tabular}{|r|c|}
\hline Cronbach's Alpha $(\boldsymbol{\alpha})$ & Keterangan \\
\hline 0,944 & Reliabel \\
\hline
\end{tabular}

Berdasarkan data pada tabel 4, nilai cronbach's alpha $(\alpha)$ bernilai 0,944. Maka instrumen pertanyaan kuesioner yang merupakan indikator dari variabel dapat dikatakan reliabel.

\section{c. Analisis Faktor}

- Kaiser-Meyer-Olkin (KMO) Measure of Sampling Adequency dan Barlett Test of Spericity.

Tabel 5. KMO Measure of Sampling Adequency dan Barlett Test of Spericity

\begin{tabular}{|l|l|r|}
\hline \multicolumn{3}{|c|}{ KMO and Bartlett's Test } \\
\hline $\begin{array}{l}\text { Kaiser-Meyer-Olkin Measure of } \\
\text { Sampling Adequacy }\end{array}$ & 0,907 \\
\hline $\begin{array}{l}\text { Bartlett's Test of } \\
\text { Sphericity }\end{array}$ & $\begin{array}{l}\text { Approx. Chi- } \\
\text { Square }\end{array}$ & 6551,298 \\
\hline & df & 1225,000 \\
\hline & Sig. & 0,000 \\
\hline
\end{tabular}

Nilai KMO Measure of Sampling Adequency pada tabel 5 ialah 0,907 , nilai tersebut lebih besar dari 0,5. Maka indikator diprediksi dan dianalisis lebih lanjut. Nilai barlett test dengan nilai siginifkansi sebesar 0,000, maka indikator berkorelasi dan dapat dianalisis lebih lanjut.

- Measure of Sampling Adequancy (MSA).

Tabel 6. Measure of Sampling Adequancy (MSA)

\begin{tabular}{|c|r|c|}
\hline Kode & \multicolumn{1}{|c|}{ MSA } & Keterangan \\
\hline KP1 & 0,854 & Valid \\
\hline KP2 & 0,899 & Valid \\
\hline KP3 & 0,865 & Valid \\
\hline KS1 & 0,905 & Valid \\
\hline KS2 & 0,906 & Valid \\
\hline KS3 & 0,855 & Valid \\
\hline PP1 & 0,926 & Valid \\
\hline PP2 & 0,795 & Valid \\
\hline PB1 & 0,834 & Valid \\
\hline PB2 & 0,879 & Valid \\
\hline PB3 & 0,85 & Valid \\
\hline PB4 & 0,953 & Valid \\
\hline PK1 & 0,927 & Valid \\
\hline PK2 & 0,631 & Valid \\
\hline PK3 & 0,9 & Valid \\
\hline PK4 & 0,886 & Valid \\
\hline PK5 & 0,875 & Valid \\
\hline KI1 & 0,888 & Valid \\
\hline KI2 & 0,923 & Valid \\
\hline
\end{tabular}

\begin{tabular}{|r|r|l|}
\hline FU1 & 0,939 & Valid \\
\hline FU2 & 0,93 & Valid \\
\hline FU3 & 0,912 & Valid \\
\hline BI1 & 0,881 & Valid \\
\hline BI2 & 0,858 & Valid \\
\hline BI3 & 0,848 & Valid \\
\hline PH1 & 0,94 & Valid \\
\hline UPR1 & 0,924 & Valid \\
\hline RK1 & 0,939 & Valid \\
\hline UPJ1 & 0,945 & Valid \\
\hline JP1 & 0,934 & Valid \\
\hline JP2 & 0,915 & Valid \\
\hline KM1 & 0,931 & Valid \\
\hline LY1 & 0,915 & Valid \\
\hline PR1 & 0,931 & Valid \\
\hline PR2 & 0,922 & Valid \\
\hline KA1 & 0,86 & Valid \\
\hline KA2 & 0,925 & Valid \\
\hline ES1 & 0,931 & Valid \\
\hline NB1 & 0,92 & Valid \\
\hline HP1 & 0,927 & Valid \\
\hline KC1 & 0,896 & Valid \\
\hline JPG1 & 0,872 & Valid \\
\hline MP1 & 0,9 & Valid \\
\hline RPG1 & 0,878 & Valid \\
\hline RMP1 & 0,952 & Valid \\
\hline KPG1 & 0,926 & Valid \\
\hline KPG2 & 0,925 & Valid \\
\hline KPU1 & 0,905 & Valid \\
\hline LO1 & 0,905 & Valid \\
\hline LO2 & 0,911 & Valid \\
\hline TO & \\
\hline
\end{tabular}

Tabel 6 menunjukkan nilai MSA pada setiap indikator memiliki nilai lebih besar dari 0,5 , artinya setiap indikator memiliki korelasi yang diharapkan dan dapat dianalisis lebih lanjut.

- Scree Plot.

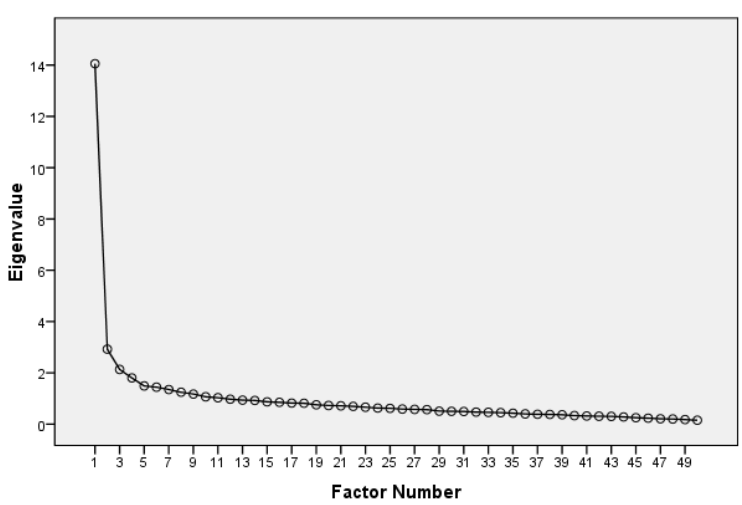

Gambar 1. Scree Plot

Gambar 1 menunjukkan bahwa bagian siku pada scree plot ditemukan pada faktor kelima. Karena faktor keenam pada scree plot terlihat sedikit menanjak ke atas. Sehingga faktor kelima merupakan batas yang dapat digunakan sebagai jumlah faktor baru (factoring). Hingga proses factoring ini, dapat diketahui bahwa dari 50 indikator yang digunakan dalam penelitian ini terbentuk 5 kelompok faktor.

Faktor Pemilihan E Marketplace di Indonesia dari Perspektif Penjual (Studi Kasus: Tokopedia dan Shopee) 
- Factor matrix dan Rotated Factor Matrix.

Tabel 7. Rotated Factor Matrix

\begin{tabular}{|c|c|c|c|c|c|}
\hline \multirow{2}{*}{ Kode } & \multicolumn{5}{|c|}{ Faktor } \\
\hline & 1 & 2 & 3 & 4 & 5 \\
\hline KPU1 & .695 & .192 & .092 & .154 & .025 \\
\hline MP1 & .675 & .245 & .004 & .077 & .083 \\
\hline KPG1 & .666 & .255 & .046 & .144 & .223 \\
\hline KPG2 & .654 & .319 & .114 & .097 & .211 \\
\hline LO1 & .636 & .262 & .082 & .169 & .071 \\
\hline JPG1 & .572 & .148 & .068 & .129 & .032 \\
\hline LO2 & .562 & .322 & .185 & .168 & .124 \\
\hline RMP1 & .527 & .211 & .165 & .061 & .326 \\
\hline ES1 & .517 & .257 & .154 & .034 & .325 \\
\hline RPG1 & .499 & .181 & .117 & .126 & .233 \\
\hline KA2 & .487 & .283 & .307 & .090 & .099 \\
\hline LY1 & .422 & .159 & .196 & .021 & .267 \\
\hline KA1 & .411 & .006 & .293 & .175 & .105 \\
\hline PR1 & .408 & .320 & .121 & .124 & .227 \\
\hline PR2 & .303 & .187 & .033 & .173 & .279 \\
\hline PB2 & .141 & .607 & .173 & .011 & .155 \\
\hline PB3 & .204 & .555 & .198 & .046 & .111 \\
\hline PK1 & .154 & .515 & .238 & .120 & .164 \\
\hline PB4 & .225 & .502 & .237 & .145 & .187 \\
\hline UPR1 & .219 & .494 & .031 & .148 & .264 \\
\hline FU1 & .203 & .476 & .174 & .170 & .256 \\
\hline JP1 & .232 & .422 & .083 & .183 & .308 \\
\hline $\mathrm{PH} 1$ & .246 & .409 & .006 & .244 & .288 \\
\hline PB1 & .117 & .408 & .115 & .077 & .019 \\
\hline RK1 & .121 & .400 & .109 & .316 & .247 \\
\hline KM1 & .186 & .386 & .157 & .240 & .369 \\
\hline UPJ1 & .238 & .371 & .095 & .316 & .316 \\
\hline PK3 & .073 & .344 & .320 & .219 & .142 \\
\hline PK2 & .068 & .308 & .042 & .042 & .028 \\
\hline PP1 & .105 & .148 & .571 & .148 & .177 \\
\hline PP2 & .061 & .029 & .561 & .109 & .025 \\
\hline KS3 & .049 & .229 & .500 & .224 & .100 \\
\hline KP2 & .238 & .309 & .469 & .081 & .104 \\
\hline KI1 & .072 & .052 & .465 & .287 & .204 \\
\hline KP3 & .282 & .337 & .388 & .086 & .015 \\
\hline PK5 & .062 & .058 & .385 & .369 & .035 \\
\hline KP1 & .294 & .309 & .366 & .075 & .021 \\
\hline KS2 & .272 & .251 & .361 & .157 & .181 \\
\hline KS1 & .289 & .277 & .324 & .217 & .117 \\
\hline $\mathrm{BI} 2$ & .112 & .046 & .195 & .731 & .019 \\
\hline $\mathrm{BI} 1$ & .111 & .102 & .096 & .607 & .097 \\
\hline $\mathrm{BI} 3$ & .169 & .019 & .238 & .517 & .007 \\
\hline FU3 & .067 & .125 & .299 & .418 & .243 \\
\hline JP2 & .251 & .326 & .130 & .368 & .249 \\
\hline FU2 & .233 & .240 & .199 & .364 & .092 \\
\hline PK4 & .131 & .179 & .255 & .323 & .093 \\
\hline NB1 & .318 & .206 & .160 & .098 & .649 \\
\hline $\mathrm{KC} 1$ & .438 & .063 & .167 & .074 & .537 \\
\hline HP1 & 409 & .211 & .089 & .114 & .467 \\
\hline $\mathrm{KI} 2$ & .035 & .306 & .368 & .186 & .398 \\
\hline
\end{tabular}

Berdasarkan hasil penelitan yang telah dilakukan, ditemukan 5 faktor yang dapat menarik penjual untuk memasarkan produknya ke situs e-marketplace Tokopedia dan Shopee. Kelima faktor ini merupakan pengelompokan dari total 50 indikator yang dapat menarik penjual untuk memasarkan produknya ke situs e-marketplace Tokopedia dan Shopee. Semua indikator memiliki factor loading di atas 0,3 . Artinya semua indikator memiliki kontribusi dalam menarik penjual untuk memasarkan produknya ke situs $e$ marketplace Tokopedia dan Shopee.

Interpretasi pendistribusian indikator pada faktor baru ditandai dengan latar warna kuning pada tabel 7 dengan penjelasan sebagai berikut:

Faktor pertama, terdiri atas lima belas indikator. Satu indikator berasal dari variabel kepuasan penjual dengan nilai loading 0.695. Satu indikator berasal dari variabel jumlah transaksi jual beli dengan nilai loading 0.675 . Dua indikator berasal dari variabel kepercayaan penjual dengan nilai loading 0.666 dan 0.654 . Dua indikator berasal dari variabel loyalitas penjual dengan nilai loading 0.636 dan 0.562 . Satu indikator berasal dari variabel jumlah pengguna yang tergabung dengan nilai loading 0.572. Satu indikator berasal dari variabel reputasi e-marketplace dengan nilai loading 0.527. Satu indikator berasal dari variabel eksplorasi dengan nilai loading 0.517. Satu indikator berasal dari variabel reputasi pengguna yang tergabung dengan nilai loading 0.499. Dua indikator berasal dari variabel keamanan dengan nilai loading 0.487 dan 0.411. Satu indikator berasal dari variabel kelengkapan layanan emarketplace dengan nilai loading 0.422 . Dua indikator berasal dari variabel promosi dengan nilai loading 0.408 dan 0.303 . Sehingga faktor ini diberi nama kepercayaan penjual.

Faktor kedua, terdiri atas empat belas indikator. Empat indikator berasal dari variabel pembayaran dengan nilai loading 0.607 , $0.555,0.502$, dan 0.408 . Tiga indikator berasal variabel pengiriman, dengan nilai loading $0.515,0.344$, dan 0.308 . Satu indikator berasal dari variabel ulasan produk dengan nilai loading 0.494. Satu indikator berasal dari variabel fungsionalitas dengan indikator keragaman kategori yang dapat diperjualbelikan dengan nilai loading 0.476. Satu indikator berasal dari variabel jenis penjual dengan indikator penjual yang beragam, dengan nilai loading 0.422 . Satu indikator berasal dari variabel pencarian harga dengan nilai loading 0.409. Satu indikator berasal dari variabel resiko kinerja dengan nilai loading 0.400 . Satu indikator berasal dari variabel komunikasi dengan nilai loading 0.386 . Satu indikator berasal dari variabel ulasan penjual dengan nilai loading 0.371.

Faktor Pemilihan E Marketplace di Indonesia dari Perspektif Penjual (Studi Kasus: Tokopedia dan Shopee) 
Sehingga faktor ini diberi nama pembayaran dan pengiriman.

Faktor ketiga, terdiri atas sepuluh indikator. Dua indikator berasal dari variabel pelayanan pelanggan dengan nilai loading 0.571 dan 0,561 . Tiga indikator berasal dari variabel kualitas situs dengan nilai loading 0.500 , 0.361 , dan 0,324 . Tiga indikator berasal dari variabel kemudahan penggunaan dengan nilai loading $0.469,0.399$, dan 0,366 . Satu indikator berasal dari variabel kualitas informasi dengan indikator kelengkapan list pertanyaan dan jawaban yang sering ditanyakan (Frequently Asked Questions/FAQ) oleh pengguna dengan nilai loading 0.465 . Satu indikator berasal dari variabel pengiriman dengan indikator asuransi pengiriman, dengan nilai loading 0.385 . Sehingga faktor ini diberi nama kualitas situs e-marketplace.

Faktor keempat, terdiri atas tujuh indikator. Tiga indikator berasal dari variabel biaya dengan nilai loading $0.731,0,607$, dan 0,517. Dua indikator berasal dari variabel fungsionalitas dengan nilai loading 0.418 dan 0.364 . Satu indikator berasal dari variabel jenis penjual dengan indikator keuntungan jenis penjual, dengan nilai loading 0.323. Satu indikator berasal dari variabel pengiriman dengan indikator pelacakan data pengiriman yang akurat, dengan nilai loading 0.323 . Sehingga faktor ini diberi nama biaya.

Faktor kelima, terdiri atas empat indikator. Satu indikator berasal dari variabel nama baik merk dengan nilai loading 0,649. Satu indikator berasal dari variabel kualitas citra produk dengan nilai loading 0.537 . Satu indikator berasal dari variabel harga produk dengan nilai loading 0.467 Satu indikator berasal dari variabel kualitas informasi dengan indikator notifikasi pemberitahuan memberikan informasi terkini, dengan nilai loading 0.398 . Sehingga faktor ini diberi nama nama baik produk.

- Uji Kesesuaian Model.

Tabel 8. Hasil Uji Kesesuaian Model

\begin{tabular}{|l|r|}
\hline \multicolumn{1}{|c|}{ Uji Kesesuaian Model } & \multicolumn{1}{|c|}{ Hasil } \\
\hline Chi-square & 6551,29 \\
\hline Significance Level & 0,00 \\
\hline CFI & 0,79 \\
\hline RMSEA & 0,06 \\
\hline
\end{tabular}

Tabel 8 menunjukkan bahwa model memiliki nilai significance level yang baik, di bawah 0,05 . CFI dengan nilai 0,79 , artinya masuk kategori marginal fit. Nilai RMSEA dengan nilai 0,06 , yang artinya juga masuk kategori marginal fit.

\section{Kesimpulan}

Berdasarkan penelitian yang telah dilakukan, maka ditemukan 5 faktor baru yang dapat menarik penjual untuk memasarkan produknya ke situs e-marketplace Tokopedia dan Shopee. Faktor-faktor tersebut adalah:
a. Kepercayaan penjual;
b. Pembayaran dan pengiriman;
c. Kualitas situs e-marketplace;
d. Biaya; dan
e. Nama baik produk.

Berikut adalah saran yang diberikan pada penelitian ini:

a. Penelitian ini hanya menerapkan metode pengumpulan data melalui kuesioner tertutup, sehingga belum mampu menggali hal yang lebih dalam. Penelitian selanjutnya diharapkan melakukan pengumpulan data dengan metode wawancara atau observasi agar dapat menggali data yang lebih dalam.

b. Penentuan jumlah faktor yang terbentuk pada penelitian ini didasarkan kepada scree plot dan nilai factor loading di atas 0,3 . Sehingga penelitian selanjutnya dapat dapat melakukan modifikasi indeks, yang melihat hasil skor uji kesesuaian model dari nilai turunan chi-square, untuk mendapatkan model yang lebih baik.

\section{Pustaka}

[1] M. S. Abdurrahman, "Pertumbuhan eCommerce Indonesia Tertinggi di Dunia," 2017. http://tekno.liputan6.com/read/2957050/ pertumbuhan-e-commerce-indonesiatertinggi-di-dunia (accessed Jan. 02, 2018).

[2] N. Amir, "Jurnal Penelitian dan Evaluasi Pendidikan," J. Penelit. Dan Eval. Pendidik., vol. 16, no. 1, pp. 246-267, 2012, doi: https://doi.org/10.21831/pep.v16i1.1120.

[3] Y. Bernarto, Innocentius; Radnan, "Pengaruh Kualitas Situs dan Kepercayaan terhadap Loyalotas Pelanggan pada Toko Online Tokopedia," 1st Natl. Semin. Small Mediu. Enterp. 2017, vol. 1, no. 1, 2017.

[4] P. Bhunia, "KOMINFO Indonesia working on number of initiatives to boost digital start-up ecosystem and support SMEs," 2017. https://www.opengovasia.com/articles/7 562-kominfo-indonesia-working-onnumber-of-initiatives-to-boost-digitalstart-up-ecosystem-and-support-smes (accessed Jan. 03, 2018).

[5] B. J. Corbitt, T. Thanasankit, and H. Yi, "Trust and e-commerce: a study of 
consumer perceptions," Electron. Commer. Res. Appl., vol. 2, pp. 203215, 2003.

[6] A. M. Damar, "comScore Resmi Jadi Pengukur Audiens Online di Indonesia," 2016.

http://tekno.liputan6.com/read/2589099/ comscore-resmi-jadi-pengukur-audiensonline-di-indonesia (accessed Jan. 17, 2018).

[7] A. Dwijayanto, "Kuartal III-2019, ecommerce besutan lokal masih perkasa - Page all," 2019. https://industri.kontan.co.id/news/kuartal -iii-2019-e-commerce-besutan-lokalmasih-perkasa?page=all.

[8] A. Farki, I. Baihaqi, and B. M. Wibawa, "Pengaruh Online Customer Review dan Rating Terhadap Kepercayaan dan Minat Pembelian pada Online Marketplace di Indonesia," J. Tek. ITS, vol. 5, no. 2, 2016, [Online]. Available: http://ejurnal.its.ac.id/index.php/teknik/ar ticle/view/19671.

[9] I. Ghozali, Aplikasi Analisis Multivariate dengan Program SPSS. Semarang: Badan Penerbit UNDIP, 2009.

[10] I. keun; Luvsanbyamba, Munkhbat; Chung, "An Empirical Study of Success Factors on From Buyers ' and Sellers ' Perspectives," ICIS '09 Proc. 2nd Int. Conf. Interact. Sci. Inf. Technol. Cult. Hum., vol. 2, no. 3, pp. 486-491, 2009, doi: 10.4156/ijipm.vol2.issue3.8.

[11] Muslim and P. I. Sandhyaduhita, "Supporting and inhibiting factors of ecommerce adoption: Exploring the sellers' side in Indonesia," Int. Conf. Adv. Comput. Sci. Inf. Syst. ICACSIS 2016, pp. 207-214, 2017, doi: 10.1109/ICACSIS.2016.7872777.

[12] Y. Nathania, "Pertumbuhan ECommerce Indonesia Meningkat Tajam, Siapa di Posisi Teratas?," 2017. https://business.idntimes.com/economy/ yoshi/pertumbuhan-e-commerce-

indonesia-1/full (accessed Jan. 02, 2018).

[13] N. I. Paramanisa, I. Darmawan, and M. A. $\mathrm{H}$, "PERANCANGAN E-COMMERCE ANGON UNTUK PELAKU PETERNAKAN BERBASIS MARKETPLACE UNTUK MENINGKATKAN KEPERCAYAAN PENGGUNA (MODUL PENGELOLAAN PEMBAYARAN DAN KELUHAN)," vol. 3, no. 2, pp. 3369-3373, 2016.

[14] A. L. W. Puranidhi, "5 Retailer dengan Pertumbuhan Pengunjung Tertinggi di 2018," 2019. https://www.liputan6.com/bisnis/read/39 06316/5-retailer-dengan-pertumbuhanpengunjung-tertinggi-di-2018 (accessed Apr. 08, 2019).

[15] V. M. Putri, "Penjual Baru di Tokopedia Melonjak di Tengah Pandemi Corona," Detik Inet. 2020, [Online]. Available: https://m.detik.com/inet/business/d4993324/penjual-baru-di-tokopediamelonjak-di-tengah-pandemi-corona.

[16] U. Radkevitch, E. Van Heck, and O. Koppius, "Leveraging Offshore IT Outsourcing by SMEs through Online Marketplaces Leveraging Offshore I T Outsourcing by SMEs through Online Marketplaces," J. Inf. Technol. Case Appl. Res., vol. 8, no. 3, pp. 37-41, 2006, doi: 10.1080/15228053.2006.10856094.

[17] A. Rahmayanti and H. Wandebori, "The Effects of E-service Quality on Customer Online Repurchase Intention Towards E-commerce Marketplace C2C in Indonesia," vol. 2016, pp. 35-40, 2016.

[18] M. Rask and H. Kragh, "Motives for emarketplace Participation: Differences and Similarities between Buyers and Suppliers," vol. 14, no. 4, pp. 270-283, 2004 , doi: 10.1080/10196780412331311720.

[19] A. Rofiq, "Terhadap Partisipasi Pelanggan," 2007.

[20] M. Saeedi, "Reputation and adverse selection: theory and evidence from eBay," RAND J. Econ., vol. 50, no. 4, pp. 822-853, 2019, doi: 10.1111/17562171.12297.

[21] N. W. Sakti, Buku Pintar Pajak ECommerce: Dari Mendaftar Sampai Membayar Pajak. Jakarta: Visimedia, 2014.

[22] M. R. Sandegi, "Faktor - Faktor Keberhasilan Proses Virtualisasi Dalam Perspektif E-Commerce Di Indonesia," INFOTEL, vol. 9, no. 2, pp. 193-197, 2017.

[23] G. J. A. Santoso and T. A. Napitupulu, "Factors affecting seller loyalty in business emarketplace: A case of Indonesia," J. Theor. Appl. Inf. Technol., vol. 96, no. 1, pp. 162-171, 2018.

[24] H. Santoso, "Mengapa Perlu Menggunakan Rekening Bersama Saat Jual Beli Online?," 2014. https://komunitas.bukalapak.com/s/je94 6j/mengapa_perlu_menggunakan_reken ing_bersama_saat_jual_beli_online (accessed Jan. 15, 2018). 
[25] S. Santoso, Statistik Multivariat. Jakarta: PT Gramedia, 2010.

[26] B. I. Sappaile, "APLIKASI ANALISIS FAKTOR DALAM PENENTUAN INDIKATOR CARA BELAJAR," J. Mat. Apl. dan Pembelajarannya, 2006.

[27] Y. Sarwono, "Pengertian Dasar Structural Equation Modeling (SEM)," J. IIm. Manaj. Bisnis Ukrida, vol. 10, no. 3, p. 98528, 2010.

[28] A. Setiawan, Edwin Hadi; Fauziah, "Pengaruh Keamanan, Kemudahan, Kepercayaan, dan Risiko Kinerja terhadap Keputusan Pembelian secara Online (Studi Kasus Tokopedia.com di Kabupaten Lumajang)," J. Ilmu Manaj. Advant., vol. 01, no. 1, pp. 64-75, 2017.

[29] F. V. Sudjatmika, "Pengaruh Harga, Ulasan Produk, Kemudahan, dan Keamanan Terhadap Keputusan Pembelian Secara Online di Tokopedia.com," Agora, vol. 5, no. 1, pp. 1-7, 2017, [Online]. Available: http://studentjournal.petra.ac.id/index.ph $\mathrm{p} /$ manajemen-

bisnis/article/view/5227\%0Ahttp://studen tjournal.petra.ac.id/index.php/manajeme n-bisnis/article/view/5227/4814.

[30] Sugiyono, Metode Penelitian Kuantitatif, Kualitatif, dan $R \& D$. Bandung: Alfabeta, Ed, 2010.

[31] T. Suwartiningsih, Sri; Sampoerno;Tanadjung, "Produksi Iklan Layanan Masyarakat Infografis: Tips Aman Belanja Online," pp. 11-27, 2016, [Online]. Available: http://repository.uksw.edu/handle/12345 $6789 / 11676$.

[32] R. S. Tombe, R. K. Ekawati, N. F. A. Budi, A. N. Hidayanto, and P. Anussornnitisarn, "Why does people use e-payment systems in $\mathrm{C} 2 \mathrm{C}$ emarketplace? a trust transfer perspective," Proc. 2nd Int. Conf. Informatics Comput. ICIC 2017, vol. 2018-Janua, pp. 1-6, 2018, doi: 10.1109/IAC.2017.8280628.

[33] K. G. I. Usadi, MPP; Rahyuda, "KONTRIBUSI SUCCESS FACTORS TERHADAP KEPUASAN PENGGUNA DAN DAMPAKNYA PADA PERILAKU PASCA PENGGUNAAN (Studi Pada Pengguna E-marketplace di Denpasar)," JUIMA, vol. 7, no. 1, 2017.

[34] W. Wang, Shan; Archer, Norman P.; Zheng, "An Exploratory Study of Electronic Marketplace Adoption: A Multiple Perspective View," Electron. Mark., vol. 16, no. 4, pp. 337-348, 2006, doi: 10.1080/10196780600999775.
[35] A. S. Wardani, "Tokopedia Kini Punya 6,4 Juta Penjual," 2019. https://www.liputan6.com/tekno/read/40 68256/tokopedia-kini-punya-64-jutapenjual.

[36] A. S. Wardani, "Pemerintah Terbitkan Roadmap e-Commerce, Ini 8 Aspek Regulasinya," 2016. http://tekno.liputan6.com/read/2648966/ pemerintah-terbitkan-roadmap-ecommerce-ini-8-aspek-regulasinya (accessed Jan. 18, 2018).

[37] M. Widiyono, Analisis pengaruh psikologi konsumen terhadap keputusan pembelian suzuki satria fu 150, vol. 150. 2014.

[38] Ag. Yasa, "Mayoritas Penjual Shopee Merupakan UMKM," 2018. https://ekonomi.bisnis.com/read/201803 30/12/755433/mayoritas-penjualshopee-merupakan-umkm.

Faktor Pemilihan E Marketplace di Indonesia dari Perspektif Penjual (Studi Kasus: Tokopedia dan Shopee) 
Lampiran Item Pernyataan Kuisisoner

\begin{tabular}{|c|c|c|c|}
\hline Sumber Referensi & Variabel & Item Pernyataan & Kode \\
\hline \multirow{3}{*}{$\begin{array}{l}\text { Rahmayanti dan Wandebori } \\
\text { (2016), Setiawan dan } \\
\text { Fauziah (2017), Sudjatmika } \\
\text { (2017), Muslim dan } \\
\text { Sandhyaduhita (2016) }\end{array}$} & \multirow{3}{*}{$\begin{array}{l}\text { Kemudahan } \\
\text { penggunaan }\end{array}$} & $\begin{array}{l}\text { Situs Tokopedia atau Shopee mudah } \\
\text { dipelajari }\end{array}$ & KP1 \\
\hline & & $\begin{array}{l}\text { Situs Tokopedia atau Shopee mudah } \\
\text { dinavigasi }\end{array}$ & KP2 \\
\hline & & $\begin{array}{l}\text { Situs Tokopedia atau Shopee mudah } \\
\text { digunakan }\end{array}$ & KP3 \\
\hline \multirow{3}{*}{$\begin{array}{l}\text { Sandegi (2017), Usadi, } \\
\text { Rahyuda, Giantari (2017), } \\
\text { Bernarto (2017) }\end{array}$} & \multirow{3}{*}{ Kualitas situs } & $\begin{array}{l}\text { Desain situs Tokopedia atau Shopee } \\
\text { menarik }\end{array}$ & $\mathrm{KS} 1$ \\
\hline & & $\begin{array}{l}\text { Tokopedia atau Shopee memiliki fitur } \\
\text { yang lengkap }\end{array}$ & KS2 \\
\hline & & $\begin{array}{l}\text { Situs Tokopedia atau Shopee merespon } \\
\text { perintah dengan cepat }\end{array}$ & KS3 \\
\hline \multirow{2}{*}{$\begin{array}{l}\text { Sandegi (2017), Usadi, } \\
\text { Rahyuda, Giantari (2017), } \\
\text { Rahmayanti dan Wandebori } \\
\text { (2016) }\end{array}$} & \multirow{2}{*}{$\begin{array}{l}\text { Pelayanan } \\
\text { pelanggan }\end{array}$} & $\begin{array}{l}\text { Ada Standar Operasional Prosedur yang } \\
\text { jelas jika terdapat keluhan dari pelanggan }\end{array}$ & PP1 \\
\hline & & $\begin{array}{l}\text { Pelayanan pelanggan Tokopedia atau } \\
\text { Shopee tanggap dalam menangani } \\
\text { keluhan }\end{array}$ & PP2 \\
\hline \multirow{4}{*}{$\begin{array}{l}\text { Sandegi (2017), Farki dan } \\
\text { Baihaqi (2016), Tombe, dkk } \\
\text { (2018) }\end{array}$} & \multirow{4}{*}{ Pembayaran } & $\begin{array}{l}\text { Rekening bersama pada Tokopedia atau } \\
\text { Shopee dapat mengurangi resiko } \\
\text { pembayaran yang tidak diinginkan }\end{array}$ & PB1 \\
\hline & & $\begin{array}{l}\text { Metode pembayaran yang disediakan } \\
\text { oleh Tokopedia atau Shopee beragam }\end{array}$ & PB2 \\
\hline & & $\begin{array}{l}\text { Konfirmasi pembayaran pada Tokopedia } \\
\text { atau Shopee cepat }\end{array}$ & PB3 \\
\hline & & $\begin{array}{l}\text { Ada manfaat yang didapatkan jika } \\
\text { menggunakan metode pembayaran } \\
\text { tertentu pada Tokopedia atau Shopee }\end{array}$ & PB4 \\
\hline \multirow{5}{*}{ Sandegi (2017) } & \multirow{5}{*}{ Pengiriman } & $\begin{array}{l}\text { Jasa pengiriman yang disediakan oleh } \\
\text { Tokopedia atau Shopee beragam }\end{array}$ & PK1 \\
\hline & & $\begin{array}{l}\text { Fitur pre-order yang disediakan oleh } \\
\text { Tokopedia atau Shopee cukup lama }\end{array}$ & PK2 \\
\hline & & $\begin{array}{l}\text { Terdapat batas waktu yang cukup yang } \\
\text { diberikan Tokopedia atau Shopee kepada } \\
\text { penjual untuk mengirimkan pesanan } \\
\text { pembeli }\end{array}$ & PK3 \\
\hline & & Pelacakan data pengiriman produk akurat & PK4 \\
\hline & & $\begin{array}{l}\text { Asuransi pengiriman produk tertentu } \\
\text { dapat diandalkan }\end{array}$ & PK5 \\
\hline \multirow[t]{2}{*}{$\begin{array}{l}\text { Usadi, Rahyuda, Giantari } \\
\text { (2017), Santoso dan } \\
\text { Napitupulu (2018) }\end{array}$} & \multirow[t]{2}{*}{$\begin{array}{l}\text { Kualitas } \\
\text { informasi }\end{array}$} & \begin{tabular}{lr} 
List pertanyaan dan jawaban yang sering \\
ditanyakan $\quad$ (Frequently & Asked \\
Questions/FAQ) & oleh pengguna \\
\multicolumn{2}{l}{ Tokopedia atau Shopee lengkap }
\end{tabular} & $\mathrm{K} 11$ \\
\hline & & $\begin{array}{l}\text { Notifikasi untuk pemberitahuan } \\
\text { memberikan informasi terkini }\end{array}$ & $\mathrm{K} 12$ \\
\hline \multirow{3}{*}{$\begin{array}{l}\text { Rahmayanti dan Wandebori } \\
\text { (2016), Rask dan Kragh } \\
\text { (2004) }\end{array}$} & \multirow{3}{*}{ Fungsionalitas } & $\begin{array}{l}\text { Kategori produk yang disediakan pada } \\
\text { Tokopedia atau Shopee cukup beragam }\end{array}$ & FU1 \\
\hline & & $\begin{array}{l}\text { Beranda dapat digunakan penjual untuk } \\
\text { mempromosikan produk }\end{array}$ & FU2 \\
\hline & & $\begin{array}{l}\text { Kuota voucher yang dapat digunakan } \\
\text { penjual untuk memberikan potongan } \\
\text { harga khusus kepada pelanggan cukup } \\
\text { banyak }\end{array}$ & FU3 \\
\hline $\begin{array}{l}\text { Santoso dan Napitupulu } \\
\text { (2018) }\end{array}$ & Biaya & $\begin{array}{l}\text { Biaya yang dibebankan kepada penjual } \\
\text { saat ada produk yang terjual cukup } \\
\text { terjangkau }\end{array}$ & $\mathrm{Bl} 1$ \\
\hline
\end{tabular}

Faktor Pemilihan E Marketplace di Indonesia dari Perspektif Penjual (Studi Kasus: Tokopedia dan Shopee) 


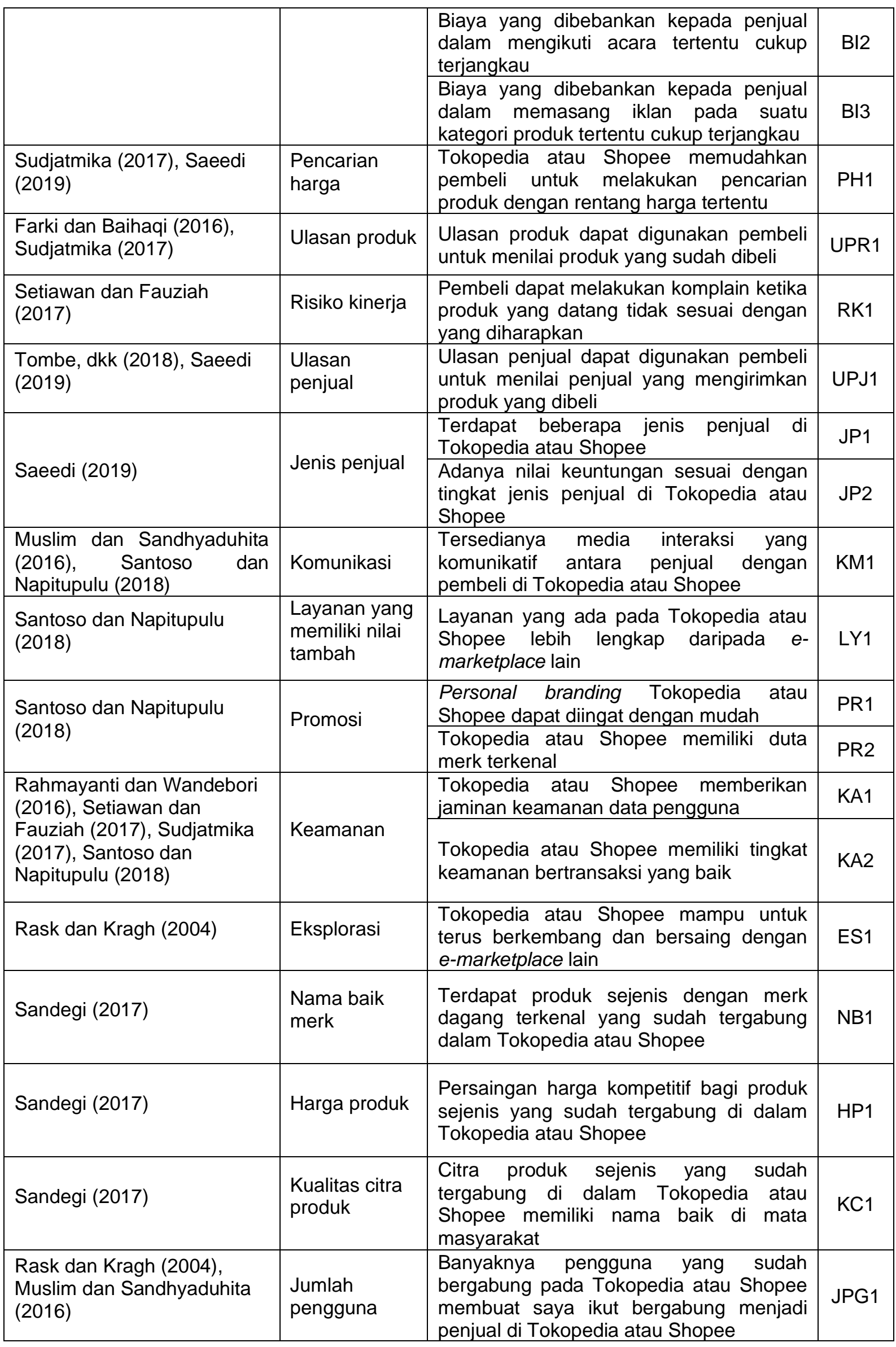




\begin{tabular}{|c|c|c|c|}
\hline $\begin{array}{l}\text { Farki dan Baihaqi (2016), } \\
\text { Usadi, Rahyuda, Giantari } \\
\text { (2017), Setiawan dan } \\
\text { Fauziah (2017), Sudjatmika } \\
\text { (2017), Muslim dan } \\
\text { Sandhyaduhita (2016) }\end{array}$ & $\begin{array}{l}\text { Minat } \\
\text { pembelian }\end{array}$ & $\begin{array}{l}\text { Banyaknya transaksi jual beli yang terjadi } \\
\text { pada Tokopedia atau Shopee membuat } \\
\text { saya ikut bergabung menjadi penjual di } \\
\text { Tokopedia atau Shopee }\end{array}$ & MP1 \\
\hline Rask dan Kragh (2004) & $\begin{array}{l}\text { Reputasi } \\
\text { pengguna }\end{array}$ & $\begin{array}{l}\text { Pengguna yang terdaftar di dalam } \\
\text { Tokopedia atau Shopee memiliki nama } \\
\text { baik di mata masyarakat }\end{array}$ & RPG1 \\
\hline $\begin{array}{l}\text { Rahmayanti dan Wandebori } \\
\text { (2016) }\end{array}$ & $\begin{array}{l}\text { Reputasi } e^{-} \\
\text {marketplace }\end{array}$ & $\begin{array}{l}\text { Situs Tokopedia atau Shopee memiliki } \\
\text { nama baik di mata masyarakat }\end{array}$ & RMP1 \\
\hline \multirow{2}{*}{$\begin{array}{l}\text { Farki dan Baihaqi (2016), } \\
\text { Tombe, dkk (2016), } \\
\text { Rahmayanti dan Wandebori } \\
\text { (2016), Bernarto (2017), } \\
\text { Setiawan dan Fauziah } \\
\text { (2017), }\end{array}$} & \multirow[t]{2}{*}{ Kepercayaan } & $\begin{array}{l}\text { Saya yakin Tokopedia atau Shopee } \\
\text { adalah situs berjualan favorit saya }\end{array}$ & KPG1 \\
\hline & & $\begin{array}{l}\text { Saya percaya Tokopedia atau Shopee } \\
\text { dapat diandalkan untuk transaksi } \\
\text { berjualan secara daring }\end{array}$ & KPG2 \\
\hline $\begin{array}{l}\text { Usadi, Rahyuda, Giantari } \\
\text { (2017), Santoso dan } \\
\text { Napitupulu (2018) }\end{array}$ & Kepuasan & $\begin{array}{l}\text { Saya merasa puas berjualan di Tokopedia } \\
\text { atau Shopee }\end{array}$ & KPU1 \\
\hline \multirow{2}{*}{$\begin{array}{l}\text { Bernarto (2017), Santoso } \\
\text { dan Napitupulu (2018) }\end{array}$} & \multirow[b]{2}{*}{ Loyalitas } & $\begin{array}{l}\text { Saya akan merekomendasikan Tokopedia } \\
\text { atau Shopee kepada orang lain }\end{array}$ & LO1 \\
\hline & & $\begin{array}{l}\text { Saya akan memberitahukan hal positif } \\
\text { Tokopedia atau Shopee kepada orang } \\
\text { lain }\end{array}$ & LO2 \\
\hline
\end{tabular}

